\title{
Definitions and diagnosis of postpartum endometritis in dairy cows
}

\author{
J. Dubuc, ${ }^{* 1,2}$ T. F. Duffield, ${ }^{*}$ K. E. Leslie, ${ }^{*}$ J. S. Walton,† and S. J. LeBlanc* \\ *Department of Population Medicine and \\ †Department of Animal and Poultry Science, University of Guelph, Guelph, Ontario, N1G 2W1, Canada
}

\section{ABSTRACT}

The objectives of this observational study were to determine and compare diagnostic criteria for postpartum endometritis in dairy cows. Data generated from 1,044 Holstein cows (6 herds) enrolled in a randomized clinical trial were used. Cows were examined for endometritis at $35 \pm 3 \mathrm{~d}$ (exam 1) and $56 \pm 3 \mathrm{~d}$ (exam 2) after parturition, using endometrial cytology (cytobrush technique), vaginal discharge scoring (Metricheck device; Simcrotech, Hamilton, New Zealand), and cervical diameter measurement (transrectal palpation). Reproductive data were recorded until $200 \mathrm{~d}$ after parturition. Diagnostic criteria for cytological and clinical endometritis were determined based on detrimental effect on subsequent reproductive performance, using logistic regression and Cox proportional hazard models accounting for the effect of herd clustering. Comparison of diagnostic criteria was performed using endometrial cytology as reference test or by quantifying the agreement between diagnostic approaches. At exam 1, diagnostic criteria were $\geq 6 \%$ polymorphonuclear cells and mucopurulent or worse (purulent or foul) vaginal discharge for cytological and clinical endometritis, respectively. At exam 2, diagnostic criteria were $\geq 4 \%$ polymorphonuclear cells and mucopurulent or worse vaginal discharge for cytological and clinical endometritis, respectively. Cows were classified as having cytological endometritis only, clinical endometritis only, or both cytological and clinical endometritis. Prevalence at exam 1 was 13.5, 9.4, and 5.8\% for cytological endometritis only, clinical endometritis only, and both cytological and clinical endometritis, respectively. The detrimental effects of cytological and clinical endometritis on reproductive performance were additive. Among cows with clinical endometritis, only 38 and $36 \%$ had cytological endometritis at exam 1 and exam 2, respectively. Combination of diagnostic criteria improved neither the accuracy for predicting cytological endometritis nor the agreement between cytological

Received May 11, 2010.

Accepted July 8, 2010.

${ }^{1}$ Corresponding author: jocelyn.dubuc@umontreal.ca

${ }^{2}$ Current address: Faculté de médecine vétérinaire, Université de Montréal, C.P. 5000, Saint-Hyacinthe, Québec, J2S 7C6, Canada. and clinical endometritis. Overall, these results suggested that cytological and clinical endometritis may represent different manifestations of reproductive tract disease. They also suggested that use of the terminology clinical endometritis may not be accurate and that purulent vaginal discharge may be more descriptive.

Key words: dairy cow, uterine disease, endometritis, diagnosis

\section{INTRODUCTION}

Postpartum endometritis in dairy cows has been defined as endometrial inflammation occurring $21 \mathrm{~d}$ or more after parturition without systemic signs of illness (Sheldon et al., 2006). Histologically, endometritis is defined as a disruption of the epithelium with presence of inflammatory cells (Bondurant, 1999). Diagnostic criteria for endometritis, using cow-side tests, have been determined based on their detrimental effect on subsequent reproductive performance (LeBlanc et al., 2002; Kasimanickam et al., 2004). Two main approaches have been used for diagnosis of endometritis: clinical and cytological.

Clinical endometritis was defined as a cervix $\geq 7.5$ $\mathrm{cm}$ in diameter by transrectal palpation $20 \mathrm{~d}$ or more after parturition or as the presence of mucopurulent or purulent vaginal discharge by vaginoscopy after $26 \mathrm{~d}$ after parturition (LeBlanc et al., 2002). The presence of mucopurulent or worse (purulent or foul) vaginal discharge during the postpartum period was also found to be detrimental to subsequent reproductive performance in seasonal calving herds (McDougall et al., 2007; Runciman et al., 2008).

Cytological endometritis was defined as an increased proportion (percentage) of polymorphonuclear cells (PMN) in endometrial cytology samples obtained by endometrial cytobrush (Kasimanickam et al., 2004) or low-volume uterine lavage (Gilbert et al., 2005) or by histology from biopsy samples (Bonnett et al., 1993). Endometrial biopsy is rarely used because it was found to be too time consuming (Etherington et al., 1988). Endometrial cytobrush and low-volume uterine lavage are the most commonly used techniques (Kasimanickam et al., 2004; Gilbert et al., 2005; Galvão et al., 2009) and they were found to provide similar results 
(Kasimanickam et al., 2005; Barlund et al., 2008). From 20 to $33 \mathrm{~d}$ after parturition, the threshold for diagnosing endometritis was $>18 \%$ PMN in a population of cows presenting no clinical signs of endometritis (Kasimanickam et al., 2004). When the population studied included all cows, without regard to the presence of clinical signs, the thresholds were $>6$ to $>8 \%$ PMN and $>4$ to $>5 \%$ PMN in different studies performed between 28 and $41 \mathrm{~d}$ and 40 and $60 \mathrm{~d}$ after parturition, respectively (Gilbert et al., 2005; Barlund et al., 2008; Galvão et al., 2009). Endometrial cytology is currently considered the reference test for endometritis because of its potential to diagnose both clinical and subclinical cases (Kasimanickam et al., 2004; Gilbert et al., 2005; Barlund et al., 2008). Subclinical endometritis refers to cows showing no clinical signs of endometritis but having an increased percentage PMN in endometrial cytology that is associated with reduced reproductive performance (Kasimanickam et al., 2004).

Interestingly, little information is available regarding the concurrent use of clinical and cytological criteria for diagnosing endometritis (Barlund et al., 2008). Most studies have used only one approach (LeBlanc et al., 2002; Kasimanickam et al., 2004; Gilbert et al., 2005). Traditionally, it has been assumed that vaginal discharge is representative of uterine health because purulent material found in the cranial vagina would likely be from uterine drainage through the cervix or from cervical infection (LeBlanc et al., 2002; McDougall et al., 2007; Runciman et al., 2009). However, no data supporting this assumption are currently available.

The performance of various diagnostic techniques for endometritis was assessed (Pleticha et al., 2009) using agreement among tests for detection of vaginal discharge (McDougall et al., 2007; Runciman et al., 2009) or compared with a reference test of endometrial cytology (Gilbert et al., 2005; Barlund et al., 2008). These diagnostic techniques have not been compared with both clinical and cytological definitions of endometritis.

Therefore, the first objective of this study was to define the optimal clinical and cytological diagnostic criteria for postpartum endometritis in dairy cows based on their effect on subsequent reproductive performance. The second objective was to compare the agreement among various diagnostic techniques for postpartum endometritis in dairy cows. The hypothesis was that clinical and cytological endometritis may be different.

\section{MATERIALS AND METHODS}

A total of 1,044 Holstein cows from 6 commercial dairy herds, including 3 in southwestern Ontario (Canada) and 3 in western New York (United States), were enrolled in this prospective observational study. The study was part of a larger research project involving a randomized clinical trial on therapies for preventing and treating uterine diseases in 2,178 Holstein cows. All cows enrolled in the present study were control animals in the clinical trial and did not receive treatments that could potentially influence their uterine health status or reproductive performance. Cows were housed in free stall barns. Herd size ranged from 300 to 1,000 lactating cows. Cows from all herds were milked 3 times daily except for 1 herd in which cows were milked twice daily. Individual cow data management was performed on farm with DairyComp 305 (Valley Agricultural Software, Tulare, CA).

Data were collected from September 2007 until November 2008. Individual cow parity group (first, second or greater) and season of calving (winter: December to February; spring: March to May; summer: June to August; fall: September to November) were recorded. Cows were enrolled only once during the duration of the study. Each farm was visited weekly by a veterinarian for data collection. All cows were examined for postpartum endometritis at $35 \pm 3 \mathrm{~d}$ (exam 1) and 56 $\pm 3 \mathrm{~d}$ (exam 2) after parturition. Prior to examination, the vulva was cleaned with paper towels. Then, a cytological sample of the endometrium from the dorsal aspect of the uterine body was collected using a cytobrush (VWR CanLab, Mississauga, Ontario, Canada) adapted for use in cattle (Kasimanickam et al., 2004, 2005; Barlund et al., 2008). Slides for cytological examination were prepared on farm by rolling the cytobrush on a clean glass microscope slide and were fixed with cytofixative (Cytoprep, Fisher Scientific, Nepean, Ontario, Canada). Slides were maintained in a transport container at a temperature greater than $10^{\circ} \mathrm{C}$ to prevent freezing. Then, transrectal palpation for determination of the cervical diameter was performed and results were classified as $<5 \mathrm{~cm}, 5$ to $7.4 \mathrm{~cm}$, and $\geq 7.5$ $\mathrm{cm}$ (LeBlanc et al., 2002). Lastly, vaginal discharge was visually examined using the Metricheck device (Simcrotech, Hamilton, New Zealand) technique and scoring: $0=$ no discharge; $1=$ clear mucus; $2=$ mucus with flecks of pus; $3=$ mucopurulent discharge; $4=$ purulent discharge; $5=$ foul smelling discharge (McDougall et al., 2007).

A total of 6 veterinarians ( 1 per herd) were involved in this study. To standardize the reporting of clinical procedures and findings, all participating veterinarians received standard instructions and documentation at the start of the study. Multiple validations of procedures and classification of findings were performed throughout the study.

All endometrial cytology slides were stained with modified Wright Giemsa stain (Protocol-Hema3, Bio- 
chemical Sciences, Swedesboro, NJ), and coverslips were applied once dry, as described elsewhere (Barlund et al., 2008). Each slide was examined at 400× magnification to perform a differential cell count of 100 cells (polymorphonuclear and endometrial cells) by a single observer. The result of this examination was reported as percentage PMN. The observer was blinded to the on-farm examination findings. This slide examination procedure was repeated twice, in 2 different locations on each slide, and the average of the results was calculated. If the 2 results had a difference $>10 \%$ PMN, a third count was performed and the average was calculated from the 2 most similar results. To determine intraobserver repeatability, a total of 200 slides were randomized and blinded to the observer for reevaluation. To validate interobserver performance, 100 randomly selected slides were examined by an external expert blinded to cow data and to the first observer's findings.

All herds exclusively used AI after a voluntary waiting period of $60 \mathrm{~d}$. All herds relied mostly on estrus detection for their first breeding at the end of the voluntary waiting period. If cows were not first bred by 70 to $80 \mathrm{~d}$ after parturition, and for subsequent breeding, cows were enrolled on an ovulation synchronization program (without presynchronization). Reproductive data of cows were collected until at least $200 \mathrm{~d}$ after parturition or until the date of culling, if earlier. Pregnancy diagnosis was performed by transrectal palpation between 35 and $49 \mathrm{~d}$ after last insemination.

Individual cow data were exported from DairyComp 305 to Microsoft Excel (Microsoft Corporation, Richmond, WA). Statistical analyses were performed in SAS (version 9.2, SAS Institute, Cary, NC) considering the cow as the unit of interest.

Postpartum endometritis was defined as the level of endometrial inflammation or the clinical findings causing impairment of subsequent reproductive performance. Dichotomization of the percentage PMN results from endometrial cytology was performed at various cut-off points to investigate what level of inflammation was detrimental to subsequent reproductive performance. This procedure was performed independently for exam 1 and exam 2. Preliminary screening of percentage PMN thresholds for classification of cows as having endometritis was done using pregnancy status $120 \mathrm{~d}$ after parturition (P120) as the outcome. Analyses in $2 \times 2$ tables were performed using the Pearson chi-squared test (FREQ procedure of SAS). Sensitivity and specificity of each threshold for predicting nonpregnancy was calculated. The thresholds with the highest combined total of sensitivity and specificity values were tested individually in logistic regression models (GLIMMIX procedure of SAS) using P120 as the outcome, a binomial distribution, and a logit link function and accounting for the fixed effects of parity group and season and the random effect of herd. The lowest percentage PMN threshold found significant $(P$ $\leq 0.05)$ was then proposed to be the optimal cut-off point for determination of cytological endometritis status. For validation purposes, the lowest significant percentage PMN threshold was tested in a Cox proportional hazard model (PHREG procedure of SAS) of time to pregnancy, controlling for the effects of parity group and season, if significant. Herds were treated as strata to account for the herd clustering effect (Gröhn et al., 1998). Unlike the previous logistic models, this Cox proportional hazard model considered reproductive data for the entire duration of study (up to $200 \mathrm{~d}$ after parturition). The assumption of proportionality of hazards in the model was assessed graphically by plotting the logarithm of the hazard functions by the logarithm of time. If predictors did not have proportional hazards over time, an interaction term of the $\log$ time at risk and the predictor was forced into the model (Dohoo et al., 2003). If cows classified as having a positive endometrial cytology had a decreased hazard of pregnancy, the diagnostic criterion was considered validated for indicating negative effect on reproductive performance in the study population. An identical approach was used for the determination of the optimal threshold for defining clinical endometritis, considering cervical diameter and vaginal discharge scores as independent variables at exam 1 and exam 2 .

Once the diagnostic criteria for cytological and clinical endometritis were established in separate models, they were combined in a final Cox proportional hazard model (PHREG procedure) for each examination period (exam 1 and exam 2) to test their interactions and to determine their effect on time to pregnancy.

After classifying the cows relative to their endometritis status (unaffected, clinical only, cytological only, or both clinical and cytological), comparison of the diagnostic techniques was performed using the FREQ procedure. Comparison considered cytological endometritis as the reference test or only agreement between methods (Barlund et al., 2008). Sensitivity, specificity, positive predictive value, negative predictive value, and agreement beyond chance (kappa statistic) were calculated for cervical diameter and vaginal discharge used alone or in combination (Dohoo et al., 2003). Intraobserver and interobserver agreement (kappa statistic; FREQ procedure) were calculated for cytological endometritis (Dohoo et al., 2003).

\section{RESULTS}

A total of 1,044 and 1,018 cows were examined for endometritis at exam 1 and exam 2, respectively. 
Table 1. Prevalence (\%) of cytological and clinical findings from examination of Holstein cows $35 \pm 3 \mathrm{~d}$ (exam 1; $\mathrm{n}=1,044$ ) and $56 \pm 3 \mathrm{~d}$ (exam $2 ; \mathrm{n}=1,018)$ after parturition, using endometrial cytobrush technique, Metricheck vaginal scoring technique, ${ }^{1}$ and the measurement of cervical diameter by transrectal palpation

\begin{tabular}{lcc}
\hline Finding & Exam 1 & Exam 2 \\
\hline Endometrial cytology (\% PMN $)^{2}$ & & \\
0 & 64.2 & 73.4 \\
$\geq 1$ & 35.8 & 26.6 \\
$\geq 2$ & 26.7 & 17.6 \\
$\geq 4$ & 21.1 & 13.8 \\
$\geq 6$ & 19.3 & 11.1 \\
$\geq 8$ & 17.4 & 9.8 \\
$\geq 10$ & 16.9 & 8.9 \\
$\geq 12$ & 16.0 & 8.4 \\
$\geq 14$ & 15.5 & 8.1 \\
$\geq 16$ & 14.4 & 7.9 \\
$\geq 18$ & 13.9 & 7.5 \\
$\geq 20$ & 13.5 & 7.2 \\
Clinical & & \\
Vaginal discharge & & \\
0 (none) & 11.2 & 12.7 \\
1 (clear mucus) & 47.5 & 52.9 \\
2 (mucus with flecks of pus) & 26.2 & 22.4 \\
3 (mucopurulent) & 8.3 & 6.6 \\
4 (purulent) & 5.8 & 4.5 \\
5 (foul) & 1.0 & 0.9 \\
Cervical diameter (cm) & & \\
$<5.0$ & 50.2 & 58.6 \\
$5.0-7.4$ & 45.4 & 38.7 \\
$\geq 7.5$ & 4.4 & 2.7 \\
\hline
\end{tabular}

${ }^{1}$ Simcrotech, Hamilton, New Zealand; McDougall et al., 2007.

${ }^{2} \% \mathrm{PMN}=$ percentage of polymorphonuclear cells.

Twenty-six cows were culled between their first and second examinations for endometritis. Table 1 describes the distribution of clinical and cytological findings from those examinations. Sensitivity and specificity as well as Pearson chi-squared tests were performed to determine the thresholds of cytological and clinical findings that had a significant association with P120 (Tables 2 and
3). The optimal thresholds for defining endometritis, based on statistical modeling, are presented in Tables 4,5 , and 6 .

Cows with $\geq 6 \%$ PMN in endometrial cytology or with a mucopurulent or worse vaginal discharge were classified as having endometritis at exam 1 . Cows with $\geq 4 \%$ PMN in endometrial cytology or with a mucopurulent vaginal discharge or worse were classified as having endometritis at exam 2. No significant interaction $(P>$ 0.05 ) was found between the 2 forms of endometritis or between diagnostic criteria and parity in the final Cox proportional hazard model for each examination time. Survival curves of time to pregnancy by endometritis status (unaffected, clinical only, cytological only, or both clinical and cytological) are presented in Figures 1 and 2 .

The overall prevalence of endometritis (cytological and clinical together) at exam 1 and exam 2 was 28.7 and $21.5 \%$, respectively. Prevalence was classified as cytological only, clinical only, or both, which were 13.5, 9.4, and 5.8\% for diagnosis at exam 1 and 9.6, 7.7, and $4.2 \%$ at exam 2, respectively. Among cows having clinical endometritis at exam 1 and exam 2, only 38.0 and $35.5 \%$, respectively, had cytological endometritis at the same time. Overall endometritis prevalence within each of the herds enrolled in the study varied between 20 and $30 \%$ and 17 and $26 \%$ at exam 1 and exam 2, respectively.

The agreement between clinical and cytological endometritis diagnostic criteria is presented in Table 7 . Using the threshold defining cytological endometritis at exam 1 and exam 2, intraobserver agreement (kappa) was 0.82 (95\% CI: $0.73-0.91 ; P<0.01)$ and interobserver agreement (kappa) was 0.77 (95\% CI: 0.69-0.85; $P<0.01)$.

Table 2. Sensitivity (Se), specificity (Sp), and significance (Pearson chi-squared; $P$-value) of thresholds of proportion of polymorphonuclear cells (\% PMN) for predicting pregnancy status $120 \mathrm{~d}$ after parturition, from cytobrush examination performed on Holstein cows $35 \pm 3 \mathrm{~d}$ (exam 1 ; $\mathrm{n}=1,044)$ and $56 \pm 3 \mathrm{~d}($ exam $2 ; \mathrm{n}=1,018)$ after parturition

\begin{tabular}{|c|c|c|c|c|c|c|c|c|c|c|}
\hline $\begin{array}{l}\text { Threshold } \\
(\% \text { PMN) }\end{array}$ & \multicolumn{5}{|c|}{ Exam 1} & \multicolumn{5}{|c|}{ Exam 2} \\
\hline$\geq 1$ & 47.0 & 42.5 & 37.7 & 66.4 & 0.19 & 47.5 & 39.7 & 28.8 & 77.3 & 0.03 \\
\hline$\geq 2$ & 47.8 & 38.7 & 29.6 & 77.5 & 0.01 & 47.4 & 35.9 & 20.3 & 86.4 & $<0.01$ \\
\hline$\geq 8$ & 48.2 & 32.0 & 21.7 & 87.7 & $<0.01$ & 47.5 & 26.6 & 13.1 & 94.1 & $<0.01$ \\
\hline$\geq 10$ & 48.0 & 32.3 & 20.9 & 88.0 & $<0.01$ & 47.3 & 25.9 & 11.9 & 95.0 & $<0.01$ \\
\hline$\geq 12$ & 48.1 & 31.0 & 20.2 & 89.1 & $<0.01$ & 47.3 & 23.8 & 11.6 & 95.7 & $<0.01$ \\
\hline$\geq 14$ & 47.9 & 31.3 & 19.4 & 89.3 & $<0.01$ & 47.4 & 23.1 & 11.4 & 95.9 & $<0.01$ \\
\hline$\geq 16$ & 47.8 & 30.7 & 18.3 & 90.2 & $<0.01$ & 47.3 & 23.7 & 11.0 & 95.9 & $<0.01$ \\
\hline$\geq 18$ & 47.7 & 31.1 & 17.6 & 90.5 & $<0.01$ & 47.3 & 23.3 & 10.6 & 96.1 & $<0.01$ \\
\hline$\geq 20$ & 47.6 & 31.3 & 17.0 & 90.7 & $<0.01$ & 47.1 & 24.3 & 10.0 & 96.1 & $<0.01$ \\
\hline
\end{tabular}

${ }^{1}$ At 120 d after parturition. 
Table 3. Sensitivity (Se), specificity (Sp), and significance (Pearson chi-squared; $P$-value) of thresholds of vaginal discharge and cervical

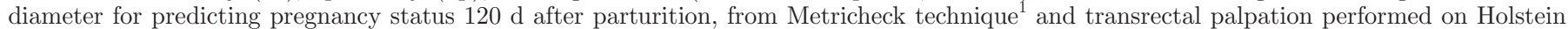
cows at $35 \pm 3 \mathrm{~d}($ exam $1 ; \mathrm{n}=1,044)$ and $56 \pm 3 \mathrm{~d}($ exam $2 ; \mathrm{n}=1,018)$ after parturition

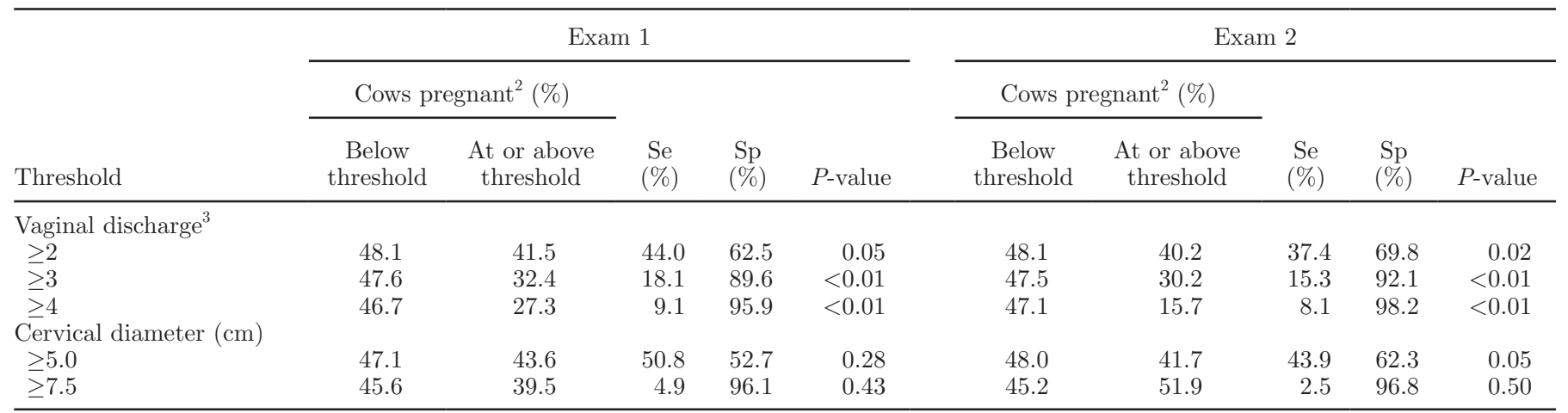

${ }^{1}$ Simcrotech, Hamilton, New Zealand; McDougall et al., 2007.

${ }^{2}$ At 120 d after parturition.

${ }^{3} \geq 2$ = mucus with flecks of pus or worse; $\geq 3=$ mucopurulent or worse; $\geq 4=$ purulent or worse.

\section{DISCUSSION}

The optimal thresholds for the diagnosis of endometritis at exam 1 were $\geq 6 \%$ PMN or mucopurulent or worse vaginal discharge. Taken individually, these diagnostic criteria are very similar to those reported ( $>6$ or $8 \%$ PMN and mucopurulent or purulent vaginal discharge) in previous studies investigating a similar time period after parturition (LeBlanc et al., 2002; Barlund et al., 2008; Galvão et al., 2009). However, the cytological threshold found in the present study differs from another frequently cited study ( $>18 \%$ PMN; Kasimanickam et al., 2004), which was performed only in cows without clinical signs of endometritis. Using the present diagnostic criteria for endometritis at exam 1, sensitivity and specificity were 33.5 and $77.5 \%$, respectively, for predicting P120. This is a higher sensitivity than reported by another study (20\%), which focused only on clinical endometritis between 20 and $33 \mathrm{~d}$ after parturition (LeBlanc et al., 2002). It appears that using both cytological and clinical criteria for diagnosis of endometritis increased the sensitivity to predict P120. However, such sensitivity for a diagnostic test remains low. Other important factors not related to uterine diseases, such as heat detection and breeding management, affect the probability of pregnancy (LeBlanc, 2005; Barlund et al., 2008).

The optimal thresholds for the diagnosis of endometritis at exam 2 were $\geq 4 \%$ PMN or mucopurulent or worse vaginal discharge. This cytological threshold is very similar to comparable studies, which reported a threshold $>4$ or 5\% PMN (Gilbert et al., 2005; Galvão et al., 2009). The sensitivity and specificity of the present diagnostic criteria for predicting P120 were 15.9 and $74.2 \%$, respectively. Thus, if one were performing only a single postpartum reproductive examination and diagnosed endometritis based on the criteria found in this study, an examination at $35 \pm 3 \mathrm{~d}$ after parturition would provide better, but still low, sensitivity for predicting P120 than an examination at $56 \pm 3 \mathrm{~d}$ after parturition.

Cytological and clinical endometritis have been shown independently (LeBlanc et al., 2002; Gilbert et al., 2005; Barlund et al., 2008) to be detrimental to subsequent reproductive performance, which is supported by the present findings. The present study was the first to address both diagnostic approaches together. When considered independently or simultaneously, cytological and clinical endometritis have negative effects on reproduction. At both endometritis examination times, cows classified positive for cyto-

Table 4. Final logistic regression models for definition of diagnostic criteria for cytological and clinical endometritis (considered separately) based on the probability of pregnancy $120 \mathrm{~d}$ after parturition, from 1,044 Holstein cows examined $35 \pm 3$ d after parturition (exam 1)

\begin{tabular}{|c|c|c|c|}
\hline Variable and class & $\begin{array}{l}\text { Odds } \\
\text { ratio }\end{array}$ & $\begin{array}{c}95 \% \\
\text { CI }\end{array}$ & $P$-value \\
\hline \multicolumn{4}{|c|}{$\begin{array}{l}\text { Cytological endometritis } \\
\geq 6 \% \mathrm{PMN}^{1}\end{array}$} \\
\hline No & Referent & & \\
\hline Yes & 0.63 & $0.45-0.89$ & $<0.01$ \\
\hline \multicolumn{4}{|l|}{ Parity } \\
\hline $\begin{array}{l}1 \\
\geq 2\end{array}$ & $\begin{array}{c}1.54 \\
\text { Referent }\end{array}$ & $1.12-2.13$ & $<0.01$ \\
\hline \multicolumn{4}{|c|}{ Clinical endometritis } \\
\hline No & Referent & & \\
\hline Yes & 0.77 & $0.56-0.97$ & 0.03 \\
\hline \multicolumn{4}{|l|}{ Parity } \\
\hline $\begin{array}{l}1 \\
\geq 2\end{array}$ & $\begin{array}{c}1.54 \\
\text { Referent }\end{array}$ & $1.10-2.18$ & $<0.01$ \\
\hline
\end{tabular}

${ }^{1}$ Percentage of polymorphonuclear cells.

${ }^{2}$ Mucopurulent or worse vaginal discharge. 
Table 5. Final logistic regression models for definition of diagnostic criteria for cytological and clinical endometritis (considered separately) based on the probability of pregnancy $120 \mathrm{~d}$ after parturition, from 1,018 Holstein cows examined $56 \pm 3$ d after parturition (exam 2)

\begin{tabular}{lccc}
\hline Variable and class & $\begin{array}{c}\text { Odds } \\
\text { ratio }\end{array}$ & $\begin{array}{c}95 \% \\
\text { CI }\end{array}$ & $P$-value \\
\hline $\begin{array}{l}\text { Cytological endometritis } \\
\geq 4 \% \text { PMN }^{1}\end{array}$ & Referent & & \\
$\quad$ No & 0.72 & $0.53-0.98$ & 0.04 \\
Yes & 1.59 & $1.15-2.19$ & $<0.01$ \\
Parity & Referent & & \\
1 & & & \\
$\geq 2$ & Referent & & \\
Clinical endometritis & 0.46 & $0.30-0.71$ & $<0.01$ \\
$\geq 3^{2}$ & & & \\
No & 1.65 & $1.20-2.26$ & $<0.01$ \\
Yes & Referent & & \\
Parity & & & \\
$\geq 2$ & & & \\
\hline
\end{tabular}

${ }^{1}$ Percentage of polymorphonuclear cells.

${ }^{2}$ Mucopurulent or worse vaginal discharge.

logical or clinical endometritis had a reduced hazard of pregnancy (hazard ratio $=0.64-0.68$ ) compared with cows classified negative for each criterion. Interestingly, the presence of both variables in the final models and the absence of significant interaction between them indicate that they may represent 2 different conditions and have additive effects on reproductive performance (Figures 1 and 2). It has been assumed in the past that the presence of purulent material in the vagina was mostly caused by drainage associated with uterine infection (LeBlanc et al., 2002). The assumption that purulent vaginal discharge is linked with the presence of endometrial inflammation has never been validated. Surprisingly, the present findings suggest that among cows with clinical endometritis, only 35.5 and $38.0 \%$ had evidence of cytological endometritis at 35 and 56 d after parturition, respectively. The low sensitivity (29.9\%) of vaginal discharge criteria alone at exam 1 for predicting cytological endometritis status also supports this idea. It is proposed that although cytological and clinical endometritis both have negative effects on reproduction, they may, in many cases, represent different manifestations of infection and inflammation in the reproductive tract. It is also proposed that clinical endometritis terminology may not be appropriate because most affected cows did not have endometrial inflammation. Thus, the use of purulent vaginal discharge may be more descriptive and appropriate. Perhaps, clinical evaluation of the reproductive tract can reveal the presence of endometritis, vaginitis, and cervicitis, and these conditions may not be differentiable by looking only at the vaginal discharge. Cytological endometritis might reflect the presence of uterine inflammation leading sometimes, but not always, to drainage of purulent material into the vagina. It is also unclear whether purulent vaginal discharge may lead to cytological endometritis. Unfortunately, the movement of purulent material from the uterus into the cervix and vagina could not be evaluated in this study, but should be considered in future studies. It is speculated that cervicitis, not necessarily reflected by an enlarged cervix, may be have a detrimental effect on subsequent reproductive performance and lead to purulent vaginal discharge.

Another potential explanation for the lack of concordance between cytological endometritis and purulent vaginal discharge could be the sampling procedures. Endometrial cytology has been proposed as the reference test to diagnose endometritis (Kasimanickam et al., 2004; Gilbert et al., 2005; Barlund et al., 2008). The cytobrush technique and low-volume uterine lavage have been shown to provide similar results (Kasimanickam et al., 2005). Although the use of the cytobrush technique in the caudo-dorsal aspect of the uterine body was the technique proposed by Kasimanickam et al. (2004), it is unknown whether sampling at different locations, such as in the uterine horns, might provide different results.

It is unclear whether the use of ultrasonography would have provided additional diagnostic information on the various manifestations of reproductive disease. The presence of uterine fluid at ultrasonographic examina-

Table 6. Final Cox proportional hazard models of the association of clinical and cytological endometritis (considered together) with the hazard ratio (HR) of pregnancy by $200 \mathrm{~d}$ after parturition, from Holstein cows examined $35 \pm 3 \mathrm{~d}$ (exam $1 ; \mathrm{n}=1,044)$ and $56 \pm 3 \mathrm{~d}($ exam $2 ; \mathrm{n}=1,018)$ after parturition

\begin{tabular}{lccccc}
\hline Variable & Coefficient & SE & HR & $95 \%$ CI & $P$-value \\
\hline Exam 1 & & & & & \\
$\geq 6 \% \mathrm{PMN}^{1}$ & -0.42 & 0.08 & 0.66 & $0.56-0.77$ & $<0.01$ \\
$\geq 3($ mucopurulent vaginal discharge or worse) & -0.45 & 0.07 & 0.64 & $0.55-0.73$ & $<0.01$ \\
Parity $\geq 2$ & -0.35 & 0.04 & 0.70 & $0.65-0.77$ & $<0.01$ \\
Exam 2 & & & & & \\
$\geq 4 \%$ PMN & -0.38 & 0.20 & 0.68 & $0.54-0.87$ & $<0.01$ \\
$\geq 3$ (mucopurulent vaginal discharge or worse) & -0.40 & 0.05 & 0.67 & $0.61-0.74$ & $<0.01$ \\
Parity $\geq 2$ & -0.33 & 0.03 & 0.72 & $0.68-0.76$ & $<0.01$ \\
\hline
\end{tabular}

$1 \% \mathrm{PMN}=$ percentage of polymorphonuclear cells. 


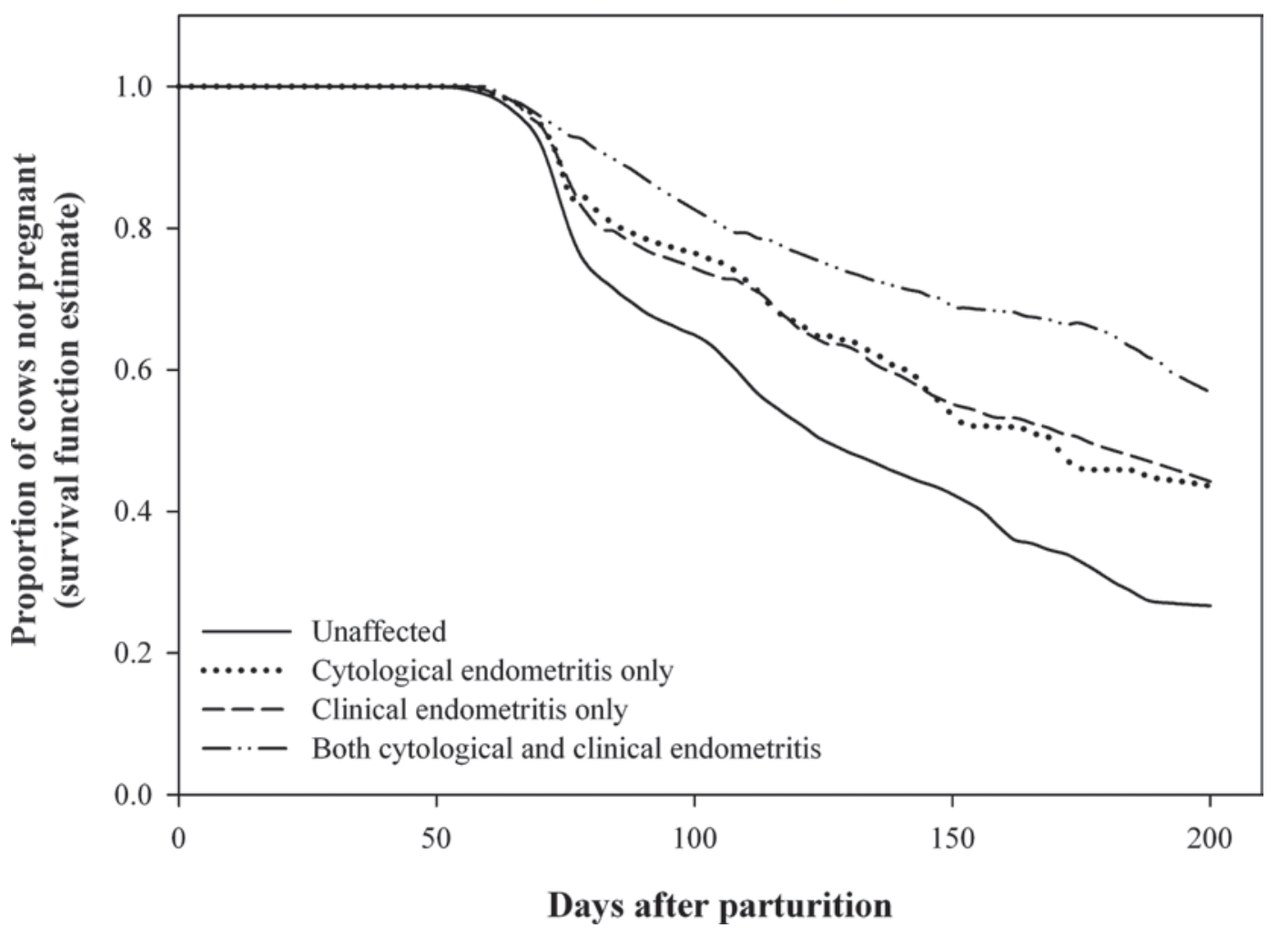

Figure 1. Survival curves for time to pregnancy up to $200 \mathrm{~d}$ after parturition in 1,044 Holstein cows examined $35 \pm 3 \mathrm{~d}$ after parturition (exam 1 ) and classified as being unaffected $(\mathrm{n}=744)$ or as having cytological endometritis only $(\geq 6 \%$ polymorphonuclear cells; $\mathrm{n}=141)$, clinical endometritis only (mucopurulent vaginal discharge or worse; $\mathrm{n}=98)$, or both cytological and clinical endometritis $(\mathrm{n}=61)$.

tion has been shown to be detrimental to reproductive performance (Kasimanickam et al., 2004). However, in that study, only $55 \%$ of cows with detectable fluid in the uterus had evidence of endometrial inflammation diagnosed by cytology (R. Kasimanickam, Washington State University, Pullman; personal communication). Unfortunately, only cows without clinical signs of endometritis were used in that study, so no variation of vaginal discharge score was available (Kasimanickam et al., 2004).

Although other studies have determined criteria similar to those of the present study for the diagnosis of cytological endometritis, great variation exists in the reported prevalence. The overall prevalence was reported to be between 11 and $53 \%$, with a variation of 0 to $74 \%$ within herd (Gilbert et al., 2005; Barlund et al., 2008; Galvão et al., 2009). In the present study, overall endometritis prevalence within each of the herds varied between 20 and $30 \%$ and 17 and $26 \%$ at exam 1 and exam 2 , respectively. The present results might not be comparable with the results of these studies because both cytological endometritis and purulent vaginal discharge were considered simultaneously in the present study. However, such a variation of the overall preva- lence between studies suggests that a small variation in the definitions used and the time period studied may be highly influential. It may also suggest that the cow populations investigated were different between studies.

Based on the effects on reproductive performance found in the present study, cytological endometritis and purulent vaginal discharge may represent different conditions. From a broader perspective, it is proposed that affected cows should be classified in 3 different uterine health statuses: purulent vaginal discharge only, cytological endometritis only, or both purulent vaginal discharge and cytological endometritis (Figure 3). This novel schematic classification supports the existence of subclinical endometritis but modifies its interpretation. Previous studies have focused on obtaining a cytological diagnosis of endometritis without exclusion of clinical cases (Gilbert et al., 2005; Barlund et al., 2008; Galvão et al., 2009), which is not equivalent to subclinical endometritis (Kasimanickam et al., 2004). Overall, results from these 2 approaches are supported by the novel classification. Further research should identify risk factors and effects for each status of endometritis to verify the distinction between them. 


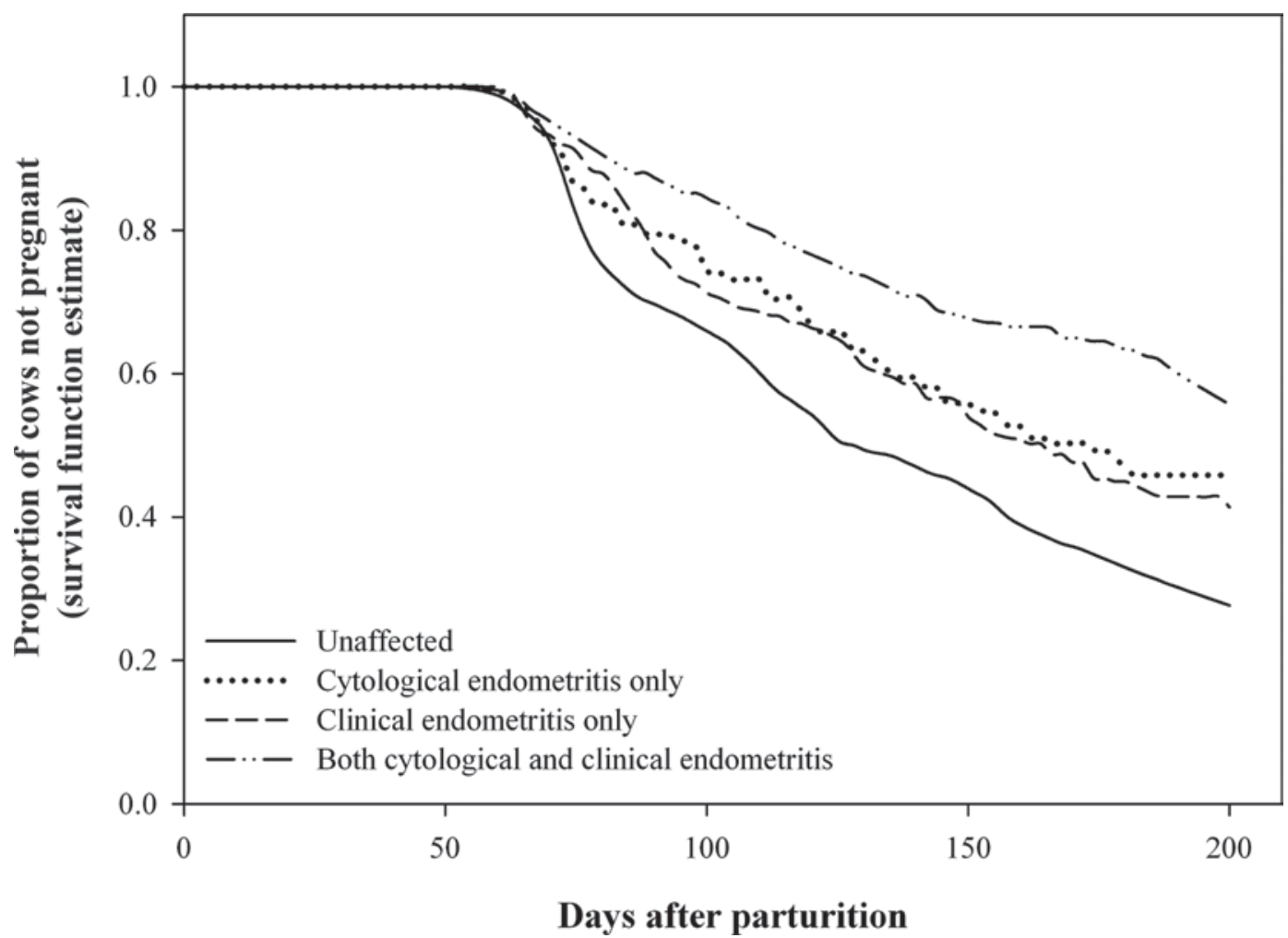

Figure 2. Survival curves for time to pregnancy up to $200 \mathrm{~d}$ after parturition in 1,018 Holstein cows examined $56 \pm 3 \mathrm{~d}$ after parturition (exam 2) and classified as being unaffected $(\mathrm{n}=800)$ or as having cytological endometritis only $(\geq 4 \%$ polymorphonuclear cells; $\mathrm{n}=97)$, clinical endometritis only (mucopurulent vaginal discharge or worse; $\mathrm{n}=78$ ), or both cytological and clinical endometritis $(\mathrm{n}=43)$.

Table 7. Agreement of diagnostic criteria for clinical endometritis and cytological endometritis $(\geq 6 \%$ polymorphonuclear cells) in 1,044 Holstein cows examined $35 \pm 3$ d after parturition (exam 1)

\begin{tabular}{|c|c|c|c|c|c|c|}
\hline Diagnostic criteria $^{2}$ & $\mathrm{n}$ & $\begin{array}{l}\mathrm{Se} \\
(\%)\end{array}$ & $\begin{array}{l}\mathrm{Sp} \\
(\%)\end{array}$ & $\begin{array}{c}\text { PPV } \\
(\%)\end{array}$ & $\begin{array}{c}\text { NPV } \\
(\%)\end{array}$ & Kappa \\
\hline \multicolumn{7}{|l|}{ VD alone } \\
\hline$\geq 2$ & 331 & 57.2 & 62.5 & 26.7 & 86.0 & 0.14 \\
\hline$\geq 3$ & 116 & 29.9 & 88.4 & 38.0 & 84.1 & 0.20 \\
\hline$\geq 4$ & 51 & 15.4 & 95.3 & 43.7 & 82.5 & 0.14 \\
\hline \multicolumn{7}{|l|}{$\overline{\mathrm{CD}}$ alone } \\
\hline$\geq 5.0$ & 398 & 64.7 & 53.7 & 25.0 & 86.4 & 0.11 \\
\hline$\geq 7.5$ & 27 & 7.5 & 96.3 & 32.6 & 81.3 & 0.05 \\
\hline \multicolumn{7}{|l|}{$\mathrm{VD}$ and $\mathrm{CD}$} \\
\hline $\mathrm{VD} \geq 2$ and $\mathrm{CD} \geq 5.0$ & 232 & 39.3 & 81.8 & 34.1 & 85.0 & 0.20 \\
\hline $\mathrm{VD} \geq 2$ and $\mathrm{CD} \geq 7.5$ & 29 & 4.5 & 98.2 & 37.5 & 81.2 & 0.04 \\
\hline $\mathrm{VD} \geq 3$ and $\mathrm{CD} \geq 5.0$ & 97 & 21.9 & 93.7 & 45.4 & 83.4 & 0.19 \\
\hline $\mathrm{VD} \geq 3$ and $C D \geq 7.5$ & 12 & 1.0 & 98.8 & 16.7 & 80.7 & 0.01 \\
\hline $\mathrm{VD} \geq 4$ and $\mathrm{CD} \geq 5.0$ & 48 & 11.4 & 97.0 & 47.9 & 82.1 & 0.12 \\
\hline $\mathrm{VD} \geq 4$ and $\mathrm{CD} \geq 7.5$ & 7 & 0.5 & 99.3 & 14.3 & 80.7 & 0.00 \\
\hline \multicolumn{7}{|l|}{$\mathrm{VD}$ or $\mathrm{CD}$} \\
\hline $\mathrm{VD} \geq 2$ or $\mathrm{CD} \geq 5.0$ & 719 & 82.6 & 34.3 & 23.1 & 89.2 & 0.09 \\
\hline $\mathrm{VD} \geq 2$ or $\mathrm{CD} \geq 7.5$ & 453 & 60.2 & 60.6 & 26.7 & 86.4 & 0.14 \\
\hline $\mathrm{VD} \geq 3$ or $\mathrm{CD} \geq 5.0$ & 581 & 72.6 & 48.3 & 25.1 & 88.1 & 0.12 \\
\hline $\mathrm{VD} \geq 3$ or $\mathrm{CD} \geq 7.5$ & 190 & 36.3 & 85.9 & 38.0 & 85.0 & 0.23 \\
\hline $\mathrm{VD} \geq 4$ or $\mathrm{CD} \geq 5.0$ & 543 & 68.6 & 51.9 & 25.4 & 87.4 & 0.12 \\
\hline $\mathrm{VD} \geq 4$ or $\mathrm{CD} \geq 7.5$ & 110 & 22.4 & 92.3 & 40.9 & 83.3 & 0.18 \\
\hline
\end{tabular}

${ }^{1} \mathrm{Se}=$ sensitivity using cytological endometritis as reference test; $\mathrm{Sp}=$ specificity using cytological endometritis as reference test; PPV = positive predictive value using cytological endometritis as reference test; NPV = negative predictive value using cytological endometritis as reference test; kappa $=$ statistic (range 0 to 1 ) for agreement beyond chance between 2 diagnostic tests when neither is assumed to be the reference test.

${ }^{2} \mathrm{VD}=$ vaginal discharge: $\geq 2=$ mucus with flecks of pus or worse; $\geq 3=$ mucopurulent or worse; $\geq 4=$ purulent or foul. $\mathrm{CD}=$ cervical diameter $(\mathrm{cm})$ 


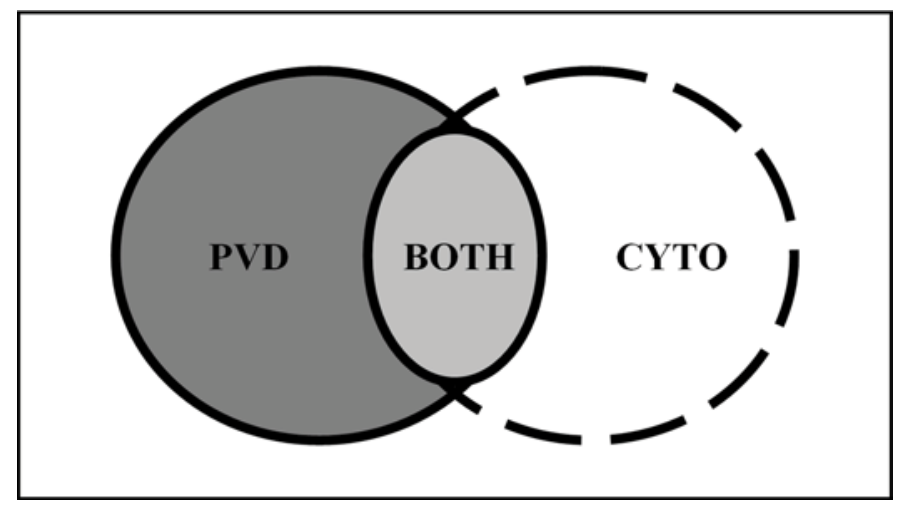

Figure 3. Novel schematic classification of postpartum uterine diseases based on the effect of diseases on subsequent reproduction in 1,044 Holstein cows examined $35 \mathrm{~d}$ after parturition, by using clinical (mucopurulent vaginal discharge or worse; solid line circle) and cytological ( $>6 \%$ polymorphonuclear cells; dotted line circle) diagnostic criteria. The figure indicates that cows could have 3 different uterine disease statuses: purulent vaginal discharge (PVD) only (dark gray area), cytological endometritis (CYTO) only (white area), or both purulent vaginal discharge and cytological endometritis (light gray area).

\section{CONCLUSIONS}

Postpartum endometritis is defined by its negative effect on subsequent reproductive performance. In this study, cytological and clinical diagnostic criteria taken together were determined to be the optimal definition of endometritis. However, overall these criteria had a low sensitivity for predicting P120, which suggests that many other reasons influence the pregnancy status at this time. Comparison of cytological (cytobrush) and clinical (Metricheck) diagnostic criteria for endometritis indicated that they may reflect different conditions. It also suggested that clinical endometritis terminology may not be appropriate and that purulent vaginal discharge may be more descriptive. Cows may be classified according to their uterine health status as purulent vaginal discharge only, cytological endometritis only, or both purulent vaginal discharge and cytological endometritis. Further research is needed to better understand the pathogenesis and mechanisms underlying these conditions.

\section{ACKNOWLEDGMENTS}

The authors acknowledge Pfizer Animal Health (New York, NY) for funding this project. They also thank the participating farmers, veterinarians, and technical staff. Gratitude is extended to Ramanathan Kasimanickam
(Washington State University, Pullman) for reviewing cytology slides as an external expert.

\section{REFERENCES}

Barlund, C. S., T. D. Carruthers, C. L. Waldner, and C. W. Palmer. 2008. A comparison of diagnostic techniques for postpartum endometritis in dairy cattle. Theriogenology 69:714-723.

Bondurant, R. H. 1999. Inflammation in the bovine female reproductive tract. J. Anim. Sci. 77(Suppl. 2):101-110.

Bonnett, B. N., S. W. Martin, and A. H. Meek. 1993. Associations of clinical findings, bacteriological and histological results of endometrial biopsy with reproductive performance of postpartum dairy cows. Prev. Vet. Med. 15:205-220.

Dohoo, I., W. Martin, and H. Stryhn. 2003. Veterinary Epidemiologic Research. 1st ed. AVC Inc., Charlottetown, Prince Edward Island, Canada.

Etherington, W. G., S. W. Martin, B. Bonnett, W. H. Johnson, R. B. Miller, N. C. Savage, J. S. Walton, and M. E. Montgomery. 1988. Reproductive performance of dairy cows following treatment with cloprostenol 26 and/or 40 days postpartum: A field trial. Theriogenology 29:565-575.

Galvão, K. N., M. Frajblat, S. B. Brittin, W. R. Butler, C. L. Guard, and R. O. Gilbert. 2009. Effect of prostaglandin F2 $\alpha$ on subclinical endometritis and fertility in dairy cow. J. Dairy Sci. 92:49064913.

Gilbert, R. O., S. T. Shin, C. L. Guard, H. N. Erb, and M. Frajblat. 2005. Prevalence of endometritis and its effects on reproductive performance of dairy cows. Theriogenology 64:1879-1888.

Gröhn, Y. T., S. W. Eicker, V. Ducrocq, and J. A. Hertl. 1998. Effect of diseases on the culling of Holstein dairy cows in New York State. J. Dairy Sci. 81:966-978.

Kasimanickam, R., T. F. Duffield, R. A. Foster, C. J. Gartley, K. E. Leslie, J. S. Walton, and W. H. Johnson. 2004. Endometrial cytology and ultrasonography for the detection of subclinical endometritis in postpartum dairy cows. Theriogenology 62:9-23.

Kasimanickam, R., T. F. Duffield, R. A. Foster, C. J. Gartley, K. E. Leslie, J. S. Walton, and W. H. Johnson. 2005. A comparison of the cytobrush and uterine lavage techniques to evaluate endometrial cytology in clinically normal postpartum dairy cows. Can. Vet. J. 46:255-259.

LeBlanc, S. 2005. Overall reproductive performance of Canadian dairy cows: Challenges we are facing. Adv. Dairy Technol. 17:137-157.

LeBlanc, S. J., T. F. Duffield, K. E. Leslie, K. G. Bateman, G. P. Keefe, J. S. Walton, and W. H. Johnson. 2002. Defining and diagnosing postpartum clinical endometritis and its impact on reproductive performance in dairy cows. J. Dairy Sci. 85:2223-2236.

McDougall, S., R. Macaulay, and C. Compton. 2007. Association between endometritis diagnosis using a novel intravaginal device and reproductive performance in dairy cattle. Anim. Reprod. Sci. 99:9-23.

Pleticha, S., M. Drillich, and W. Heuwieser. 2009. Evaluation of the Metricheck device and the gloved hand for the diagnosis of clinical endometritis in dairy cows. J. Dairy Sci. 92:5429-5435.

Runciman, D. J., G. A. Anderson, and J. Malmo. 2009. Comparison of two methods of detecting purulent vaginal discharge in postpartum dairy cows and effect of intrauterine cephapirin on reproductive performance. Aust. Vet. J. 87:369-378.

Runciman, D. J., G. A. Anderson, J. Malmo, and G. M. Davis. 2008. Use of postpartum vaginoscopic (visual vaginal) examination of dairy cows for the diagnosis of endometritis and the association of endometritis with reduced reproductive performance. Aust. Vet. J. $86: 205-213$.

Sheldon, I. M., G. S. Lewis, S. LeBlanc, and R. O. Gilbert. 2006. Defining postpartum uterine disease in cattle. Theriogenology 65:1516-1530. 